\title{
Ethics of Digital Animal Farming
}

\author{
Suresh Neethirajan ${ }^{1 *}$ \\ ${ }^{1}$ Adaptation Physiology Group, Animal Sciences Department, Wageningen University \& Research, \\ Wageningen, The Netherlands
}

* Correspondence:

Suresh Neethirajan

suresh.neethirajan@wur.nl

Keywords: Precision Livestock Farming, Sensors, Animal Ethics, Animal Welfare, Society, Sustainability, Human-animal relationships

\begin{abstract}
The demand for animal products is expected to continue to rise, which requires the development of efficient livestock farming systems. Environmental, societal and economic concerns regarding this industry are however accumulating, addressing the large resource demand, pollutants and greenhouse gas emissions and health concerns that the livestock industry is responsible for. Precision livestock farming systems allow the continuous automatic monitoring of various physiological, behavioural and phenotypic parameters of animals in order to increase productivity and animal welfare while controlling and minimizing the environmental impact. There is a high potential for digital farming to be the solution for responsibly and ethically feeding the growing and urbanizing population. However, many problems and concerns are still present in this developing industry and remain relatively unaddressed, starting with the ethical aspects in regard to the animal, including its objectification, human-animal relationships and welfare and ending with the societal implications of this digitalization. Concrete frameworks, inter-disciplinary studies and global legislation need to be put in place in order to ensure the safety and protection of the animals, farmer and society. Here, implications of digital farming for the animals, farmers, society and the planet are critically reviewed with the future outlook of digital farms.
\end{abstract}

\section{Introduction}

In this digital age, smart systems are becoming more frequent everywhere around us - they exist in homes, cars, energy management, logistics, and healthcare, amongst others. Such systems sense particular parameters to understand and analyze a situation, after which decisions can be made to control or act upon the situation. Recently, the uses of smart systems have developed beyond direct uses for humans only, for example for dog training or smart pet feeders. Smart systems are becoming more common to monitor production animals too (Neethirajan, 2020a), in order to improve their welfare and maximize productivity of the farm. Although the implications of such precision livestock farming methods are widespread, numerous ethical and moral concerns are raised as a consequence. How invasive can the sensors be for the animal, how is the data stored and secured and who does it belong to, and what implications do smart animal monitoring systems have for the farmers and the planet? Here, we outline the ethics and implications of digital farming and the future outlooks of this promising, yet complex industry. 


\section{What is precision livestock farming?}

It has been predicted that by 2050 , the demand for farm animal production will have doubled due to the exponential population growth accompanied by rising wealth (Nikos and Bruinsma, 2012). The farming industry therefore is challenged with an increasing demand for animal products, while needing to take into account the rising concerns about the health and welfare of the animals (Spain et al., 2018) plus the environmental and societal consequences of livestock farming. This leads us to the question how farms can respond ethically, morally, efficiently and responsibly to this rising demand. Laws and regulations keep appearing in different countries all over the world in order to improve animal welfare, however many health issues in farm animals continue to persist including lameness and mastitis (Whay and Shearer, 2017), but also behavioral problems due to the unnatural environment farm animals spend their entire life in, which can limit their ability to express their natural behaviors (Vigors et al., 2021). Moreover, numerous reports highlight how the intensification of livestock farming contributes to environmental problems, including increased greenhouse gas emissions, pollution and health problems (Sakadevan and Nguyen, 2017). Therefore, there is a high need for sustainable solutions within the livestock farming industry to increase efficiency and animal welfare while minimizing the environmental impact.

Smart precision livestock technologies using sensors and models allow the automatic and continuous collection, processing and analysis of various types of data by applying the principles of process engineering to livestock farming (Neethirajan, 2020b). Precision livestock farming (PLF) allows 24/7 monitoring and surveillance of farm animals, both on the level of the individual and the group. Types of data that can be collected are animal growth, productivity (such as milk, meat or egg production), diseases, animal behavior, fertility, and physical / environmental parameters, such as the temperature, humidity and lighting (Halachmi and Guarino, 2016). PLF technologies interlink such processes to form a complex network through artificial intelligence, and based on the collected data, management decisions could be taken to prevent injury and disease, improve overall welfare and enhance production efficiency (Neethirajan and Kemp, 2021). Warnings, notifications and alarms could be triggered through continuous data collection based on multiple sensors. Types of variables that can be monitored non-invasively, simultaneously and automatically range from image to sound analyses that can be used to e.g. track locomotion, activity, facial expression and behavior (Norton et al., 2019). Examples of applications of PLF are detecting estrus prior to insemination (Mottram, 2016), adapting feeding to maximize weight gain (Parsons et al., 2007), detecting aggression in pigs (Lee et al., 2016), identifying heat stress (Pereira and Nääs, 2008), determining stereotypies such as pecking behavior in poultry (Gates and Xin, 2008) and detecting disease (Buller et al., 2020) e.g. through automatically detecting coughing in pigs (Guarino et al., 2008; Benjamin and Yik, 2019).

\section{Promises of precision livestock farming}

The uses of precision livestock farming are very widespread and although most attention has been given to improve efficiency and production (Vieira Rios et al., 2020), increasing focus is being put on the monitoring of animal behavior to address animal welfare issues (Berckmans, 2014; Blokhuis et al., 2019). PLF can manage and control inputs and outputs of the systems objectively, continuously and automatically, rather than the livestock farmer needing to make management decisions on subjective judgement of the situation. Moreover, through using applications on mobile devices, farmers are able to monitor and be aware of their animals even remotely. Furthermore, as large datasets are collected with PLF, such information on animal performance and the performance of the farm could be shared with other involved parties. Such benefits would allow the control of harmful pollutants (such as ammonia), create efficient systems based on objective measures, and opens up the possibility of early detection of behavioral or physical problems of the individual animals, increasing their welfare. 
Endemic outbreaks could therefore be prevented through proactive measures and early detection of disease (Akhigbe et al., 2021).

Automated production methods have been used for a few decades, such as automatic milking systems in dairy cows, and neck-cutting systems in poultry (Buller et al., 2020). Even though these systems can therefore become quick and efficient, saving time, effort and money (Berckmans, 2008; LunnerKolstrup, Hörndahl and Karttunen, 2018), it has also reduced the direct contact between the farmer and their livestock, which could reduce their ability to determine the animal's welfare (Waiblinger et al., 2006; Hostiou, Fagon, Chauvat, Turlot, Klinkg-Eveillard, et al., 2017). Many critics of PLF thus stress the lack of human-animal relationships when the majority of farming practices are being taken over my automated systems, increasing the objectification of animals (Bos et al., 2018). There are many ethical considerations to be taken regarding digital farming, affecting not only the animals but also the farmers, and in turn society and the environment.

\section{Implications of digital farming for the animals}

Animals are sentient beings, and compiling evidence shows that their minds are complex and that nonhuman animals can show different emotions, cognitive abilities and intelligence, too (Morris, Doe and Godsell, 2008; Balcombe, 2009; King, 2013; Harris and Prouvost, 2014; Lexcellent, 2019). However, Nussbaum has described how the industrial farming industry in general resonates treating the animals as inert (without agency or activity), fungible, owned by humans (Nussbaum, 1995), and as lacking autonomy (Bos et al., 2018). The question then arises how precision livestock farming changes the ethics of animal farming, and how appreciation and respect for their sentience, emotions, intelligence and welfare is incorporated in the technological system.

As mentioned before, precision livestock farming has received criticism due to the increased objectification of animals, which has the potential to lead to denying their feelings and interests (Harfeld et al., 2016). Even though this seems contradictory as one of the goals of PLF is to increase animal welfare, the animals become just another element in the system and they can become "living parts of a machinery" (Harfeld et al., 2016). This in turn facilitates the detachment of the humans from the animals (Bos et al., 2018). The farmer-animal relationship plays an important role in the degree of objectification, whether this is intentional or unintentional (Papadaki, 2010). As the animals are dependent on us, care ethics highlight how we have to practice values of attentiveness, competence, responsibility and responsiveness (Anthony, 2012). Care theory demands that farm animals need to be raised by humans in caring ways, starting with the respect of the other's nature where the animal's body language, including eye movement, facial expression and vocalizations, is important to establish sympathy, empathy and compassion (Engster, 2006). Without farmers being physically present, these processes are solely dependent on the functioning, efficiency and accuracy of automated sensors and systems. The human-animal relationship becomes dependent on artificial intelligence and insights from animal scientists and process engineers, while the farmer's focus might drift away from qualifying individual animals. Moreover, an increasing digitalization of the industry puts the animals even further away from their natural habitats, which might facilitate animal objectification (Harfeld et al., 2016).

Not only is the concept and its bearings of precision livestock farming raising questions on the ethicality, but also the acquisition of data itself and how it is interpreted. Starting off with the types of sensors and technologies, these should be non-invasive to reduce any adverse effects on animal welfare by the devices themselves. Devices should be of such low weight that it cannot cause physical discomfort or injury, nor should it impact animal behavior (Schillings et al., 2021) and the electric fields should not impact health, which has not been shown so far but requires further attention (Benaissa et al., 2018). When it comes to data interpretation, a holistic approach incorporating multiple 
different data types is crucial to get a full understanding of the situation and how to act upon it through detecting small changes (Hemeryck et al., 2015; Poria et al., 2017).

A crucial component in the principles of PLF are the target values which are used to compare the measured variables against, based on economic, quality and/or environmental criteria. Such measures can be the leanness of a broiler chicken, or the level of pollutants like ammonia that have been emitted (Wathes et al., 2008; Van Hertem et al., 2018). These target values therefore have to be carefully determined and this brings moral values and priorities with it (Bos et al., 2018). Moreover, it is important that these target values are not interfered with by fluctuating external factors, so the technologies have to be validated in different environments and conditions, and have to be able to deal with different weather issues while insuring proper and stable internet access (Schillings et al., 2021). The algorithms must also be able to take into account inter-individual differences between animals, while considering variation between breeds and rearing environment, too, without anthropomorphizing (Wilson et al., 2019; Schillings et al., 2021; Ziesche, 2021). Anthropomorphizing the sentience and feelings of other animals, i.e. attributing human traits to non-human animals, can lead to humans being biased towards assessing other animals' emotions as we assess them through our eyes only (Leitsberger et al., 2016). A moral concern and an objective method to analyze emotions without relating them back to our own is essential to train these models accurately. There are also other concerns when it comes to optimizing the environment with the purpose of the efficiency of technologies, which might impact the animals. This can range from different light-dark regimes or light intensity, to creating a more monotone environment to reduce visual or auditory noise. Technologies are able to help with many things simultaneously, such as animal welfare and productivity, but in extreme situations they may not be mutually maximizable which leads to a need to prioritize one aspect over the other, bearing ethical implications (Werkheiser, 2020).

One way to fully acknowledge the respect or infringement of the principles of precision livestock farming is to conduct an extensive bioethical analysis for each digital system in each species. One of such bioethical analysis has been conducted by researchers (Wathes et al., 2008), analyzing automatic milking systems for dairy cows. Bioethical analyses identify ethical issues transparently, objectively and systematically by a knowledgeable committee of judges, and therefore provide a solid framework to assess the ethics per system (Wathes et al., 2008). Other solutions to avoid the objectification of animals might be to address the autonomy of the animals, such as cows that can choose when they want to be milked by the robotic facility, after they are rewarded with feed (Stuart, Schewe and Gunderson, 2013).

\section{Implications of precision livestock farming for the farmers}

As machines and technologies largely take over the labor of the farmer, farm management and practices quickly change, too. It is important to highlight the voice of the individual farmer and the stakeholders that are involved, as many ethical questions arise regarding access, cost, scale and support within digital farming. Precision livestock farming lifts off a large amount of repetitive tasks off the farmer (KlingEveillard et al., 2020), but brings up new challenges and the need for specialist knowledge, skills and advisory support in order to control and interpret the machineries (Schillings, Bennett and Rose, 2021). PLF might also reduce the farmer's autonomy as they are getting more and more dependent on technological devices, drastically shifting what the job involves and changing farmer identity (Klerkx, Jakku and Labarthe, 2019; Kling-Eveillard et al., 2020; Pol et al., 2021). It has therefore been highlighted by the farmers that the decision making process should still be done by the farmer itself and PLF should only function as a useful guiding tool (Hartung et al., 2017). As the digitalization of farming requires literacy in the digital world, this might discriminate against those who do not have these skills and this can affect marginalized groups plus separate labor and capital (Klerkx, Jakku and Labarthe, 2019). The information provided by the systems can be complex and difficult to interpret, 
which might increase the mental workload and negatively affect the farmers (Hostiou, Fagon, Chauvat, Turlot, Kling-Eveillard, et al., 2017). Furthermore, automation of tasks will not only change jobs, but it will also lead to job losses on the farm.

In order to create a cost-effective system, trust of the farmer and advisor is essential and this trust also links to how the data are handled, including ownership, accessibility, usage and storage, and how to avoid cyber-crime (Carbonell, 2016; Jakku et al., 2019; Wiseman et al., 2019). Legal and regulatory frameworks for these aspects are still missing and this forms a challenge to the farmers, leading to their reluctance to adopt smart systems within their farm. A study on Australian farmers shows that their main concerns regarding smart farming are the lack of transparency regarding data ownership, privacy, portability, trust and liability between the farmers and other commercial parties (Wiseman et al., 2019). Often, contracts between farmers and agricultural service providers are very detailed and complex, and it might be difficult to understand the implications of such a contract. Moreover, the contracts are nonnegotiable, so the farmers have to either take it or leave it, reducing their level of trust and confidence in what they sign up for. One method to increase the clarity of data sharing, ownership, consent and disclosure, is to implement agricultural-data codes of practice (Sanderson, Wiseman and Poncini, 2018). It is the ethical responsibility of all parties involved to protect not only the animals, but also the farmer, especially as there is a huge division of power between the large multinational technology corporations compared to those to contribute to the data (Jakku et al., 2019).

\section{Impact of precision livestock farming on society and the planet}

Precision livestock farming has been advocated for as a means of addressing environmental, economic and social issues regarding intensive large-scale livestock farming (Balafoutis et al., 2017; Van Hertem, Lague and Vranken, 2018). The extent to which these claims have been supported by evidence and quantified is however, minimal. This intensification has implications for the perception of food safety and food security, sustainability, animal welfare, and health issues (both animal and human) (Winter et al., 2017; Lovarelli, Bacenetti and Guarino, 2020).

Scholten and colleagues have described a conceptual framework for sustainable livestock farming based on care ethics, that do not only include principles regarding the animals, but relate it back to societal implications, too (Scholten et al., 2013). They base their framework on four areas: One Health (animal and human health and safety through disease prevention and reduce antibiotic use to prevent resistance), Customized Care (to ensure dignity and integrity of individual animals, improving animal welfare), No Nuisance (reduce pollution including emission of pollutants but also noise and pathogens) and Credible Performance (to guarantee trust for farmers from a local to global perspective) (Scholten et al., 2013). Their framework incorporated the ethics of all different aspects of digital farming - from the animal to the planet.

Human health is affected by the livestock industry as microbial and parasite resistance keeps increasing, which therefore demands a reduction of the use of antibiotics to prevent this. Using animal sensors could identify ill animals in early stages, therefore reducing the need to treat all animals (Barwick et al., 2018). Moreover, animal rearing and the management of manure and slurry leads to emissions of greenhouse gases, acidification and eutrophication and resource depletion (Hostiou, Fagon, Chauvat, Turlot, Kling-Eveillard, et al., 2017; Provolo et al., 2018). Technological approaches such as PLF can provide solutions to reduce air, soil and water pollutants including ammonia, nitrous oxide, carbon dioxide and methane (Bell et al., 2011; Hou, Velthof and Oenema, 2015; Dominiak and Kristensen, 2017; Todde et al., 2017; Balaine et al., 2020), as well as to reduce energy consumption (Todde et al., 2017) and enhance economic sustainability (Balaine et al., 2020). Furthermore, the constant monitoring of different aspects also allows traceability of the products, providing a more transparent method to the consumer, too (Neethirajan and Kemp, 2021). PLF offers a promising 
connection between different economic, environmental and societal sustainability aspects, including health conditions, welfare, production and sustainability (Lovarelli, Bacenetti and Guarino, 2020).

It is essential however, to understand the attitudes of consumers and the public towards digital farming. Not only is a detailed understanding of this digitalization of the industry required, but also its implications, benefits and disadvantages. Without public acceptance, the industry cannot be further developed. Results in different European countries show that there is a general positive reaction to the potential of farming technologies, through enhancing health and welfare of the animals and addressing environmental issues (Krampe et al., 2021; Pfeiffer, Gabriel and Gandorfer, 2021), but other citizens' attitudes can be negative (Giersberg and Meijboom, 2021). When presented with pictures of such digital systems, respondent's attitudes changed to a negative association and criticism (Pfeiffer, Gabriel and Gandorfer, 2021), and many fears are present including the intense industrialization of livestock farming and data misuse and criminality (Krampe et al., 2021). Such studies shows that the promising aspects of precision livestock farming cannot neglect the societal attitude towards this digitalization, and that such surveys can contribute to the development of PLF technologies. In addition, not only attitudes of citizens are important, but also those of other actors including veterinarians and stakeholders other than farmers whom have not been studied yet to date (Giersberg and Meijboom, 2021).

\section{Challenges and future outlook of digital farms}

Another challenge of digital farming is to quantify the added value of PLF to the individual farm and the industry as a whole. Many studies have investigated the impacts, increases in productivity and other aspects of digital farming on small scales, but it is important to quantify how precision livestock farming would change the industry when looking at it on a larger scale. The term value of information has been used to indicate not only the economic gains and losses, but also non-economic ones including health, welfare and social well-being of decision makers (Rojo-Gimeno et al., 2019). Assessing such a value is inevitably complex due to the need to translate information back to value, but it is important for both the farmer's attitude towards PLF and society's, and to understand how the high initial investment in the technologies will pay back over time (Akhigbe et al., 2021). Rojo-Gimeno and colleagues addressed the framework needed for this assessment and highlight the lack of evidence of improved value of digital farming technologies, but also the how the specificity of each farm and its requirements influence the added value (Rojo-Gimeno et al., 2019). Whereas one farm might be challenged with particular health issues of its animals, and others by the level of emissions caused by the farm's practices, this would drastically change the added value of digital farming systems depending on the individual farm and its needs. In addition to a need for the quantification of the value of information, a Life Cycle Assessment, the cost for Life Cycle and Social Life Cycle Assessment should be conducted in order to assess the environmental sustainability between farms that do and do not adopt PLF (Lovarelli et al., 2020). 
Table 1. Summary of the (ethical) implications of precision livestock farming per level.

\section{Level Potential improvements}

\section{Concerns and knowledge gaps}

- Could lead to increased objectification of animals, being just another part of the system and through digitalization of the habitat

- Automatic and continuous sampling of objective parameters to improve health and welfare

- Potential for increased autonomy such as choosing when to be milked

- Limits repetitive, time- and laborconsuming tasks done by the farmer

- Increases productivity while minimizing environmental impact leading to potential more income after initial investment

- Automatic and constant monitoring of the entire farm, even remotely

- Addresses the increasing customer demand for better animal welfare

- Decreases farm animal and human health issues by reducing disease and the need for antibiotics

- Can aid to reduce pollution, emissions of greenhouse gases and energy consumption
- Decreases human-animal interactions

- Accuracy, reliability and efficiency of the machinery needs to be validated

- Algorithms and target values have to be carefully considered to take into account individual differences

- A holistic, multi-modal approach has to be taken to assess each machinery per species, e.g. through a bioethical analysis

- Need for new specialist, digital skills and advisory support

- Reduces farmer's autonomy as they depend more on technology

- Changes the job and will lead to job losses

- Interpretation of complex systems can increase mental workload

- Lack of trust between farmer and tech companies

- Lack of a framework regarding data ownership, usage, storage and misuse

- Provides more transparency towards the costumer due to increased traceability

- Still a lack of public acceptance but society is also relatively unaware about the advantages and disadvantages of PLF

- Other attitudes are still unknown, such as of veterinarians and stakeholders

- The added value of PLF has not been quantified yet and there is a need for Life Cycle Assessment

There are still numerous theoretical and technical challenges to be addressed, including validating the algorithms to ensure situations are accurately analyzed and acted upon, but also to ensure the safety, privacy and protection of the farmers and their data. The data collected by different sensors need not only to be validated and reliable, but also communicate among each other to avoid false alarms but also prevent missing important events (Lovarelli, Bacenetti and Guarino, 2020). Different frameworks have been laid out to address challenges within the development of digital farming, such as the Livestock Farming with Care framework (Scholten et al., 2013), frameworks for bioethical analyses (Wathes et al., 2008) and methods to assess the value of information (Rojo-Gimeno et al., 2019), but 
a need for a cross-industry approach involving different experts is still required. This would involve not only the farmer and the technology companies, but also scientists, food chain actors, policymakers, NGOs and funders in order to get a full perspective on the system, including the ethical implications for each party and the system as a whole. A summary of all the implications of PFL on each different level can be found in Table 1 .

\section{Conclusions}

Precision livestock farming has a high potential to improve social, economic and environmental sustainability and animal welfare, however there are still many knowledge gaps and concerns that need to be addressed. Sensors and automatization are able to replace the eyes, nose and ears of the livestock farmer continuously, during day and night. There are currently no standards or guiding principles in deploying digital technologies such as blockchain or sensors in enabling precision livestock farming. The technological methods required for PLF need a high collaboration accompanied with trust amongst different fields including researchers in disciplines such as animal scientists, data scientists and engineers, but also farmers, veterinarians and different stakeholders. The combination of such professions allows the improvement within the industry, while taking into account different ethical aspects, perspectives and concerns. Moreover, the respect for farm animals has to be prioritized to ensure that the animals are protected from unintentional harm while digitizing farming. The lack of regulatory control in precision livestock farming technologies and the common standards are a serious issue and therefore, further research is needed to be able to scientifically back up the ethicality of the initiatives and inform broadly heterogenous and multi-sectoral stakeholders. Moreover, it is crucial that the farmer's voice is not ignored and that the systems are transparent, clear, understandable and function mostly as an advisory and helping tool. The purpose of the digital systems should not only focus on increasing productivity and profitable gains, but also animal welfare and careful frameworks need to be put in place in order to act morally and ethically towards each party involved. The gap between the unknown and known risks in deployment of digital platforms demands the consideration of ethical risks, benefits and principles in the implementation.

\section{Conflict of Interest}

The author declare that the research was conducted in the absence of any commercial or financial relationships that could be construed as a potential conflict of interest.

\section{Funding}

This research received no external funding.

\section{References}

Akhigbe, I. et al. (2021) 'Iot technologies for livestock management: A review of present status, opportunities, and future trends bernard', Big Data and Cognitive Computing, 5(1). doi: 10.3390/bdcc5010010.

Anthony, R. (2012) 'Building a Sustainable Future for Animal Agriculture: An Environmental Virtue Ethic of Care Approach within the Philosophy of Technology', Journal of Agricultural and Environmental Ethics, 25(2), pp. 123-144. doi: 10.1007/s10806-010-9285-z.

Balafoutis, A. et al. (2017) 'Precision Agriculture Technologies Positively Contributing to GHG Emissions Mitigation, Farm Productivity and Economics', Sustainability, 9(8), p. 1339. doi: $10.3390 /$ su9081339.

Balaine, L. et al. (2020) 'Can technology help achieve sustainable intensification? Evidence from milk 
recording on Irish dairy farms', Land Use Policy. Elsevier, 92(June 2019), p. 104437. doi: 10.1016/j.landusepol.2019.104437.

Balcombe, J. (2009) 'Animal pleasure and its moral significance', Applied Animal Behaviour Science, 118(3-4), pp. 208-216. doi: 10.1016/j.applanim.2009.02.012.

Barwick, J. et al. (2018) 'Categorising sheep activity using a tri-axial accelerometer', Computers and Electronics in Agriculture, 145, pp. 289-297. doi: 10.1016/j.compag.2018.01.007.

Bell, M. J. et al. (2011) 'The effect of improving cow productivity, fertility, and longevity on the global warming potential of dairy systems', Journal of Dairy Science, 94(7), pp. 3662-3678. doi: 10.3168/jds.2010-4023.

Benaissa, S. et al. (2018) 'Numerical assessment of EMF exposure of a cow to a wireless power transfer system for dairy cattle', Computers and Electronics in Agriculture, 151, pp. 219-225. doi: 10.1016/j.compag.2018.06.017.

Benjamin, M. and Yik, S. (2019) 'Precision Livestock Farming in Swine Welfare: A Review for Swine Practitioners', Animals, 9(4), p. 133. doi: 10.3390/ani9040133.

Berckmans, D. (2008) 'Precision livestock farming (PLF)', Computers and Electronics in Agriculture, 62(1), p. 1. doi: 10.1016/j.compag.2007.09.002.

Berckmans, D. (2014) 'Precision livestock farming technologies for welfare management in intensive livestock systems', Revue Scientifique et Technique de l'OIE, 33(1), pp. 189-196. doi: 10.20506/rst.33.1.2273.

Blokhuis, H. J. et al. (2019) 'Safeguarding farm animal welfare', in Sustainability Certification Schemes in the Agricultural and Natural Resource Sectors. Outcomes for Society and the Environment. Vogt, M. London, UK: Routledge, pp. 137-153.

Bos, J. M. et al. (2018) 'The Quantified Animal: Precision Livestock Farming and the Ethical Implications of Objectification', Food Ethics. Food Ethics, 2(1), pp. 77-92. doi: 10.1007/s41055-01800029-x.

Buller, H. et al. (2020) 'Animal welfare management in a digital world', Animals, 10(10), pp. 1-12. doi: 10.3390/ani10101779.

Carbonell, I. M. (2016) 'The ethics of big data in big agriculture', Internet Policy Review, 5(1). doi: 10.14763/2016.1.405.

Dominiak, K. N. and Kristensen, A. R. (2017) 'Prioritizing alarms from sensor-based detection models in livestock production - A review on model performance and alarm reducing methods', Computers and Electronics in Agriculture, 133, pp. 46-67. doi: 10.1016/j.compag.2016.12.008.

Engster, D. (2006) 'Care ethics and animal welfare.', Journal of Social Philosophy, 37(4), pp. 521536.

Gates, R. S. and Xin, H. (2008) 'Extracting poultry behaviour from time-series weigh scale records', Computers and Electronics in Agriculture, 62(1), pp. 8-14. doi: 10.1016/j.compag.2007.08.015.

Giersberg, M. F. and Meijboom, F. L. B. (2021) 'Smart Technologies Lead to Smart Answers? On the Claim of Smart Sensing Technologies to Tackle Animal Related Societal Concerns in Europe Over Current Pig Husbandry Systems', Frontiers in Veterinary Science, 7(January). doi: $10.3389 /$ fvets.2020.588214.

Guarino, M. et al. (2008) 'Field test of algorithm for automatic cough detection in pig houses', Computers and Electronics in Agriculture, 62(1), pp. 22-28. doi: 10.1016/j.compag.2007.08.016. 
Halachmi, I. and Guarino, M. (2016) 'Editorial: Precision livestock farming: a "per animal” approach using advanced monitoring technologies', Animal, 10(9), pp. 1482-1483. doi: 10.1017/S1751731116001142.

Harfeld, J. L. et al. (2016) 'Seeing the Animal: On the Ethical Implications of De-animalization in Intensive Animal Production Systems', Journal of Agricultural and Environmental Ethics, 29(3), pp. 407-423. doi: 10.1007/s10806-016-9611-1.

Harris, C. R. and Prouvost, C. (2014) 'Jealousy in Dogs', PLoS ONE. Edited by E. Z. Cameron, 9(7), p. e94597. doi: 10.1371/journal.pone.0094597.

Hartung, J. et al. (2017) 'European farmers' experiences with precision livestock farming systems', Animal Frontiers, 7(1), pp. 38-44. doi: 10.2527/af.2017.0107.

Hemeryck, M. et al. (2015) 'The Pig Cough Monitor in the EU-PLF project results and multimodal data analysis in two case studies.', in Proceedings of The 7th European Conference on Precision Livestock Farming (EC-PLF). Milan, Italy, pp. 147-155.

Van Hertem, T., Lague, S. and Vranken, E. (2018) 'Objective sustainability assessment by Precision Livestock Farming', No. 2133-2018-5441. doi: 10.22004/ag.econ.276210.

Hostiou, N., Fagon, J., Chauvat, S., Turlot, A., Klinkg-Eveillard, F., et al. (2017) 'Impact of precision livestock farming on work and human- animal interactions on dairy farms. A review', Biotechnol. Agron. Soc. Environ., 21(4), pp. 268-275.

Hostiou, N., Fagon, J., Chauvat, S., Turlot, A., Kling-Eveillard, F., et al. (2017) 'Impact of precision livestock farming on work and human-animal interactions on dairy farms. A review', Biotechnol. Agron. Soc. Environ., 21(4), pp. 268-275.

Hou, Y., Velthof, G. L. and Oenema, O. (2015) 'Mitigation of ammonia, nitrous oxide and methane emissions from manure management chains: a meta-analysis and integrated assessment', Global Change Biology, 21(3), pp. 1293-1312. doi: 10.1111/gcb.12767.

Jakku, E. et al. (2019) "“If they don't tell us what they do with it, why would we trust them?" Trust, transparency and benefit-sharing in Smart Farming', NJAS - Wageningen Journal of Life Sciences, 9091, p. 100285. doi: 10.1016/j.njas.2018.11.002.

King, B. (2013) 'When Animals Mourn', Scientific American, 309(1), pp. 62-67. doi: $10.2307 / 26017823$.

Klerkx, L., Jakku, E. and Labarthe, P. (2019) 'A review of social science on digital agriculture, smart farming and agriculture 4.0: New contributions and a future research agenda', NJAS - Wageningen Journal of Life Sciences. Elsevier, 90-91(November), p. 100315. doi: 10.1016/j.njas.2019.100315.

Kling-Eveillard, F. et al. (2020) 'Farmers' representations of the effects of precision livestock farming on human-animal relationships', Livestock Science. Elsevier B.V., 238(April), p. 104057. doi: 10.1016/j.livsci.2020.104057.

Krampe, C. et al. (2021) 'Consumer perceptions of precision livestock farming - a qualitative study in three european countries’, Animals, 11(5), pp. 1-13. doi: 10.3390/ani11051221.

Lee, J. et al. (2016) 'Automatic Recognition of Aggressive Behavior in Pigs Using a Kinect Depth Sensor’, Sensors, 16(5), p. 631. doi: 10.3390/s16050631.

Leitsberger, M., Benz-Schwarzburg, J. and Grimm, H. (2016) 'A Speaking Piglet Advertises Beef: An Ethical Analysis on Objectification and Anthropomorphism', Journal of Agricultural and Environmental Ethics, 29(6), pp. 1003-1019. doi: 10.1007/s10806-016-9644-5. 
Lexcellent, C. (2019) ‘Animal Intelligence’, in, pp. 51-52. doi: 10.1007/978-3-030-21445-6_6.

Lovarelli, D., Bacenetti, J. and Guarino, M. (2020) 'A review on dairy cattle farming: Is precision livestock farming the compromise for an environmental, economic and social sustainable production?', Journal of Cleaner Production. Elsevier Ltd, 262, p. 121409. doi: 10.1016/j.jclepro.2020.121409.

Lunner-Kolstrup, C., Hörndahl, T. and Karttunen, J. P. (2018) 'Farm operators' experiences of advanced technology and automation in Swedish agriculture: a pilot study', Journal of Agromedicine, 23(3), pp. 215-226. doi: 10.1080/1059924X.2018.1458670.

Morris, P. H., Doe, C. and Godsell, E. (2008) 'Secondary emotions in non-primate species? Behavioural reports and subjective claims by animal owners', Cognition and Emotion, 22(1), pp. 320. doi: 10.1080/02699930701273716.

Mottram, T. (2016) 'Animal board invited review: precision livestock farming for dairy cows with a focus on oestrus detection', Animal, 10(10), pp. 1575-1584. doi: 10.1017/S1751731115002517.

Neethirajan, S. (2020a). 'Transforming the adaptation physiology of farm animals through sensors'. Animals , 10 (9), pp. 1-24. doi: 10.3390/ani10091512.

Neethirajan, S. (2020b). The role of sensors, big data and machine learning in modern animal farming. Sensing and Bio-Sensing Research, 100367, pp. 1-8. doi: 10.1016/j.sbsr.2020.100367.

Neethirajan, S. and Kemp, B. (2021) 'Digital Livestock Farming', Sensing and Bio-Sensing Research. Elsevier B.V., 32(February), p. 100408. doi: 10.1016/j.sbsr.2021.100408.

Nikos, A. and Bruinsma, J. (2012) World agriculture towards 2030/2050: the 2012 revision. doi: 10.22004/ag.econ.288998.

Norton, T. et al. (2019) 'Review: Precision livestock farming: Building "digital representations" to bring the animals closer to the farmer', Animal. Elsevier, 13(12), pp. 3009-3017. doi: 10.1017/S175173111900199X.

Nussbaum, M. C. (1995) 'Objectification', Philosophy and Public Affairs, 24(4), pp. 249-291. doi: 10.1111/j.1088-4963.1995.tb00032.x.

Papadaki, L. (2010) 'What is Objectification?', Journal of Moral Philosophy, 7(1), pp. 16-36. doi: 10.1163/174046809X12544019606067.

Parsons, D. J. et al. (2007) 'Real-time Control of Pig Growth through an Integrated Management System’, Biosystems Engineering, 96(2), pp. 257-266. doi: 10.1016/j.biosystemseng.2006.10.013.

Pereira, D. F. and Nääs, I. A. (2008) 'Estimating the thermoneutral zone for broiler breeders using behavioral analysis', Computers and Electronics in Agriculture, 62(1), pp. 2-7. doi: 10.1016/j.compag.2007.09.001.

Pfeiffer, J., Gabriel, A. and Gandorfer, M. (2021) 'Understanding the public attitudinal acceptance of digital farming technologies: a nationwide survey in Germany', Agriculture and Human Values. Springer Netherlands, 38(1), pp. 107-128. doi: 10.1007/s10460-020-10145-2.

Pol, F. et al. (2021) 'Human-animal relationship influences husbandry practices, animal welfare and productivity in pig farming', Animal. The Authors, 15(2), p. 100103. doi: 10.1016/j.animal.2020.100103.

Poria, S. et al. (2017) 'A review of affective computing: From unimodal analysis to multimodal fusion', Information Fusion. Elsevier B.V., 37, pp. 98-125. doi: 10.1016/j.inffus.2017.02.003.

Provolo, G. et al. (2018) 'Global warming and acidification potential assessment of a collective manure 
management system for bioenergy production and nitrogen removal in northern Italy', Sustainability, 10(10), p. 3653. doi: 10.3390/su10103653.

Rojo-Gimeno, C. et al. (2019) 'Assessment of the value of information of precision livestock farming: A conceptual framework', NJAS - Wageningen Journal of Life Sciences. Elsevier, 90-91(November 2018), p. 100311. doi: 10.1016/j.njas.2019.100311.

Sakadevan, K. and Nguyen, M.-L. (2017) 'Livestock production and its impact on nutrient pollution and greenhouse gas emissions’, in, pp. 147-184. doi: 10.1016/bs.agron.2016.10.002.

Sanderson, J., Wiseman, L. and Poncini, S. (2018) 'What's behind the ag-data logo? An examination of voluntary agricultural-data codes of practice', International Journal of Rural Law and Policy, (1). doi: 10.5130/ijrlp.1.2018.6043.

Schillings, J., Bennett, R. and Rose, D. C. (2021) 'Animal welfare and other ethical implications of Precision Livestock Farming technology', CABI Agriculture and Bioscience. BioMed Central, 2(1), pp. 2-5. doi: 10.1186/s43170-021-00037-8.

Scholten, M. C. T. et al. (2013) 'Livestock Farming with Care: towards sustainable production of animal-source food', NJAS - Wageningen Journal of Life Sciences, 66, pp. 3-5. doi: 10.1016/j.njas.2013.05.009.

Spain, C. et al. (2018) 'Are They Buying It? United States Consumers' Changing Attitudes toward More Humanely Raised Meat, Eggs, and Dairy', Animals, 8(8), p. 128. doi: 10.3390/ani8080128.

Stuart, D., Schewe, R. L. and Gunderson, R. (2013) 'Extending Social Theory to Farm Animals: Addressing Alienation in the Dairy Sector', Sociologia Ruralis, 53(2), pp. 201-222. doi: 10.1111/soru. 12005 .

Todde, G. et al. (2017) 'Energy and Carbon Impact of Precision Livestock Farming Technologies Implementation in the Milk Chain: From Dairy Farm to Cheese Factory', Agriculture, 7(10), p. 79. doi: 10.3390/agriculture7100079.

Vieira Rios, H. et al. (2020) 'How are information technologies addressing broiler welfare? A systematic review based on the welfare quality assessment', Sustainability, 12(4), p. 1413. doi: $10.3390 /$ su12041413.

Vigors, B., Ewing, D. A., \& Lawrence, A. B. (2021). 'The importance of farm animal health and natural behaviors to livestock farmers: Findings from a factorial survey using vignettes'. Frontiers in Animal Science, 2, 638782, pp. 1-21. doi: 10.3389/fanim.2021.638782.

Waiblinger, S. et al. (2006) 'Assessing the human-animal relationship in farmed species: A critical review', Applied Animal Behaviour Science, 101(3-4), pp. 185-242. doi: 10.1016/j.applanim.2006.02.001.

Wathes, C. M. et al. (2008) 'Is precision livestock farming an engineer's daydream or nightmare, an animal's friend or foe, and a farmer's panacea or pitfall?', Computers and Electronics in Agriculture, 64(1), pp. 2-10. doi: 10.1016/j.compag.2008.05.005.

Werkheiser, I. (2020) 'Technology and responsibility: A discussion of underexamined risks and concerns in precision livestock farming', Animal Frontiers, 10(1), pp. 51-57. doi: 10.1093/af/vfz056.

Whay, H. R. and Shearer, J. K. (2017) 'The impact of lameness on welfare of the dairy cow', Veterinary Clinics of North America: Food Animal Practice, 33(2), pp. 153-164. doi: 10.1016/j.cvfa.2017.02.008.

Wilson, V. et al. (2019) 'Future directions for personality research: Contributing new insights to the understanding of animal behavior', Animals, 9(5), p. 240. doi: 10.3390/ani9050240. 
Winter, L. et al. (2017) 'Including biodiversity in life cycle assessment - State of the art, gaps and research needs', Environmental Impact Assessment Review, 67, pp. 88-100. doi: 10.1016/j.eiar.2017.08.006.

Wiseman, L. et al. (2019) 'Farmers and their data: An examination of farmers' reluctance to share their data through the lens of the laws impacting smart farming', NJAS - Wageningen Journal of Life Sciences, 90-91, p. 100301. doi: 10.1016/j.njas.2019.04.007.

Ziesche, S. (2021) 'AI Ethics and value alignment for nonhuman animals', Philosophies, 6(2), p. 31. doi: 10.3390/philosophies6020031. 